\title{
EFFECT OF GRAPE SEED EXTRACT SOLUTION ON THE MICROHARDNESS OF THE ROOT CANAL DENTIN: AN IN VITRO STUDY
}

\author{
SYLVA ALINDA*, ANGGRAINI MARGONO, DINI ASRIANTI \\ Department of Conservative Dentistry, Faculty of Dentistry, Salemba Raya No. 4, Universitas Indonesia, Central Jakarta 10430, Jakarta, \\ Indonesia. Email: sylvaalinda@ui.ac.id
}

Received: 01 August 2019, Revised and Accepted: 19 February 2020

\section{ABSTRACT}

Objective: Grape seed extract (GSE) containing proanthocyanidin as a root canal irrigation solution has its antibacterial effects and ability to eliminate the smear layer. In addition, proanthocyanidin acts as a cross-linking agent of collagen, which adds to dentin's mechanical properties. This study analyzed the effect of GSE containing 2.9\% proanthocyanidin on the microhardness of the dentin in the root canal.

Methods: Fifty teeth were divided into three groups and immersed in GSE solution, 3\% NaOCl solution, or distilled water (controls) for 30 min for 3 consecutive days. The microhardness was measured using the Vickers method. Data were analyzed using the Kruskal-Wallis test.

Results: The GSE group presented the highest microhardness values, whereas the lowest values in the NaOCl group. No significant difference in microhardness observed between the GSE and distilled water groups.

Conclusion: The GSE solution maintains the microhardness of the root canal dentin.

Keywords: Grape seed extract, Proanthocyanidin, Microhardness, Root canal dentin.

(C) 2020 The Authors. Published by Innovare Academic Sciences Pvt Ltd. This is an open access article under the CC BY license (http://creativecommons. org/licenses/by/4. 0/) DOI: http://dx.doi.org/10.22159/ijap.2020.v12s2.PP-16

\section{INTRODUCTION}

One of the primary purposes of endodontic treatment is hermetic obturation. A tight apical seal prevents the entry of bacteria and its products into the root canal. Low-quality root canal obturation increases the risk of microleakage, which results in endodontic treatment failure; apical microleakage is the most common cause of endodontic treatment failure. The method used to obturate the root canal influences the occurrence of the apical leakage, the formation of the smear layer, and the adhesion of the root canal filling material [1].

The chemical irrigants commonly used in endodontic treatment have certain disadvantages because they can alter the composition of the dentin's inorganic and organic contents, mainly collagen. Type I collagen is the main constituent of the organic structure of the dentin. It acts as a scaffold and forms a framework for the mineralized material, determining the dentin's mechanical properties [2]. Changes in the inorganic structure of the dentin and the components of the root canal due to the use of chemical irrigation solutions can increase the risk of vertical root fractures in post-endodontic teeth [3]. Alterations in the organic and inorganic components of the dentin seen in scanning electron microscope images as cracks in the intertubular dentin after irrigation with EDTA (17\%) and $\mathrm{NaOCl}(2.5 \%)$ [4]. Besides, the damaged dentin collagen interferes with the formation of a hybrid layer that can affect the adhesion of the root canal sealant to the dentin [5]. One of the mechanical properties which decreased after the use of the root canal irrigation solution was microhardness - an indication of the decrease in the condition of the collagen. The damaged condition of the collagen in the root canal can reduce the adhesion of root canal sealer to the dentin, leading to microleakage and root canal failure. As a result, studies on the use of natural materials as antibacterial root canal irrigation solutions that did not reduce dentin's mechanical properties have been conducted $[5,6]$.

Prevention of damage to dentin's collagen by the formation of collagen bonds is more stable and resistant to biodegradation. The application of a collagen cross-linking agent can maintain collagen stability. One of the natural collagen cross-linking agents that have recently studied is a component of grape seed extract (GSE) called proanthocyanidins $[7,8]$. GSE solutions have been shown to have antibacterial properties and can eliminate the smear layer $[9,10]$. Furthermore, GSE has shown to have a positive effect on some of the mechanical properties of dentin, such as flexural strength and microhardness [6].

However, GSE's effect on the microhardness of the dentin in the root canal has not evaluated so far. This study aimed to analyze the effect of GSE (containing $2.9 \%$ of proanthocyanidin) on the microhardness of the root canal dentin.

\section{MATERIALS AND METHODS}

\section{Specimens}

Until the experiment starts, 50 human single root premolars extracted for orthodontic purposes stored in saline solution. The apical portions of the teeth prepared with a diamond disk and chisel under water spray. The apical third of the tooth was sectioned into $5 \mathrm{~mm}$ dentin disks in a mesiodistal direction, parallel to the longitudinal axis of the tooth. All the samples rinsed with saline solution, and each dentin disk embedded in an acrylic resin block with the inner side of the root canal exposed. All samples stored in a closed container with a saline solution to maintain dentin hydration until further use $[11,12]$.

\section{Groups}

The root canal dentin disks randomly divided into three groups based on the irrigation solution they immersed in: Group $1(n=30)$ immersed in GSE with proanthocyanidin (2.9\%), Group $2(\mathrm{n}=30)$ immersed in sodium hypochlorite ( $\mathrm{NaOCl} ; 3 \%$ ), and Group 3 (controls: $\mathrm{n}=30$ ) immersed in distilled water. Each sample immersed in $5 \mathrm{~mL}$ of irrigation solution, 30 min per day for 3 consecutive days $[13,14]$.

\section{Measurement}

The microhardness measurement uses the Vickers method with $500 \mathrm{~g}$ per $15 \mathrm{~s}$ indentations [14]. Three indentation points measured in each 
sample. The measurements took at the Balai Besar Teknologi Kekuatan Struktur (Center for Structural Strength Technology), Pusat Penelitian Ilmu Pengetahuan dan Teknologi (Research, Science and Technology Center), South Tangerang, Indonesia.

\section{Statistical analysis}

The data were tabulated and statistically analyzed using the Kruskal-Wallis and post hoc Mann-Whitney U tests. The level of significance was 5\%. All data were analyzed using IBM SPSS Statistics Software, version 20 (IBM Corp., Armonk, NY, USA)

\section{RESULTS AND DISCUSSION}

\section{Root canal dentin microhardness value}

The highest median microhardness observed in Group 1 (GSE group) followed by Group 3 (distilled water) and Group 2 (NaOCl; Table 1). Likewise, the highest average value of dentin root canal microhardness was Group 1 followed by Group 3 and Group 2. The highest microhardness value measured in the $2.9 \%$ GSE group was $32.21 \pm 15.14$ $\mathrm{HV}$, and the lowest value in the $3 \% \mathrm{NaOCl}$ group was $21.24 \pm 9.23 \mathrm{HV}$. No significant difference in microhardness value noted between Group 1 and Group 3 (controls).

\section{Irrigation solution influence to dentin's microhardness}

Chemomechanical preparation is one of the most critical factors that determine the success of root canal treatment. The $3 \% \mathrm{NaOCl}$ irrigation solution commonly used for endodontic treatment has antibacterial activities and dissolves the necrotic tissue in the root canal [15]. However, it alters the composition of the organic and inorganic structures of the tooth $[13,14]$. Moreover, it is toxic to the tissues due to its chemical nature [16]. Therefore, various studies evaluating the potential of natural materials for use as root canal irrigation solutions have been conducted $[5,6,9,10,17,18]$.

GSE is one such natural ingredient, which contains a high proportion of proanthocyanidin. GSE solution has shown to eliminate the root canal smear layer and act against Enterococcus faecalis [9,10]. Another advantage of GSE is the ability to increase collagen cross-linking, which can improve the quality of the organic and inorganic tooth structures, thus increasing dentin's mechanical properties $[5,6,17]$.

Dentin microhardness, one of the dentin's mechanical properties, is influenced by the amount of collagen matrix and mineral component in the dentin. Collagen acts as a scaffold for mineralized material in the dentin, resulting in the association between the amount of dentin collagen matrix and minerals contained in dentin. As the amount of collagen matrix formed on the dentin increases, the mineral component also increases. The increase in dentin microhardness indicated by an increase in the number of calcified matrices per $\mathrm{mm}^{2}$. Therefore, microhardness measurements have commonly used to demonstrate the loss or increase of minerals in hard tooth tissues, including dentin $[19,20]$.

Changes may occur in the organic and inorganic components of the dentin in post-endodontically treated root canals. One such change is the decrease in microhardness, commonly caused by the irrigation solutions used for endodontic treatment [13]. The decrease in microhardness provides evidence of the reduction in the dentin's inorganic components and an overview of the dentin collagen matrix's condition. These changes result in the formation of cracks in the intertubular dentin, which will reduce the resistance of the root canal

Table 1: Value of root canal dentin microhardness after the experiment

\begin{tabular}{llll}
\hline Experimental groups & Median (min-max) & Mean \pm SD & p-value \\
\hline $2.9 \% \mathrm{GSE}$ & $27.04(9.92-63.34)$ & $32.21 \pm 15.14$ & 0.002 \\
$3 \% \mathrm{NaOCl}$ & $19.75(6.83-43.88)$ & $21.24 \pm 9.23$ & 0.002 \\
Distilled water & $26.31(8.86-59.14)$ & $29.55 \pm 12.63$ & 0.002 \\
\hline
\end{tabular}

wall and increase the risk of fractures in the endodontically treated teeth [4].

Damage to the dentinal collagen after the use of the $\mathrm{NaOCl}$ irrigation solution disrupts the formation of a hybrid layer due to the formation of an oxygen-rich layer on the dentin; this eliminates the organic matrix (collagen) and exposes the dentin surface, thus affecting the seal against the dentin [5]. The adhesion of the root canal sealer affects the quality of the root canal obturation. It determines the success of the treatment [1].

\section{Proanthocyanidin in GSE as cross-linking agent}

GSE contains proanthocyanidin, which is known to have antibacterial properties, can eliminate smear layers, and improve dentin's mechanical properties. Proanthocyanidins can induce the crosslinking of collagen molecules in the dentin by increasing the number of inter- and intra-molecular collagen cross-links, thus strengthening the dentin collagen matrix and increasing the stability of the collagen by preventing enzymatic degradation, which in turn will improve the mechanical properties of dentin $[5,17]$.

Proanthocyanidin molecules consist of multiple free phenyl hydroxyl groups that contain free hydroxyl groups, which can form bridgetype hydrogen bonds with the side chains of hydroxyl, carboxyl, amino, and collagen molecular amides. The formation of hydrogen bonds causes the stability of proanthocyanidin-collagen interactions. Furthermore, because of its position between the collagen molecules, proanthocyanidin can form ionic and covalent bonds with collagen fibrils [21]. During the process of forming hydrogen bonds, proanthocyanidin molecules can replace water molecules that bind to collagen in the extra fibrils [21]. This results in cross-linking and the formation of more stable collagen, thus enabling the maintenance of the mineral component and microhardness of the root canal dentin.

The GSE (Vitis vinifera) used in this study originates from Turkey and has used to prepare solutions for healthy drinks. The majority of the local grape varieties cultivated in Indonesia belong to this type [22]. The climate conditions in the lowlands with the hot weather and loose sandy soil in Indonesia, especially in Bali, Kediri, and Probolinggo, are suitable for grape cultivation. The weather does not affect the quality of the wine originating from Indonesia, as well as the quality of the wine from Europe and Central Asia [23,24].

The local GSE is processed based on the concentration of GSE in the solution. According to Angellina (2013), the GSE solution's concentration did not affect the ability to clean the smear layer in the root canal [9]. GSE is an irrigation solution that cleanses the smear layer not based on the GSE concentration. However, the role of GSE in the cross-linking of the collagen influenced by the concentration of proanthocyanidin. Based on several previous studies, $3.75 \%$ and $6.5 \%$ of proanthocyanidin in GSE can significantly increase collagen crosslinking $[25,26]$. Additional studies are required to evaluate the effects of various concentrations of proanthocyanidin in GSE on the dentin in the root canal.

\section{Application of irrigation solution}

The $3 \% \mathrm{NaOCl}$ solution in this study based on a previous study by Ghonmode et al. (2013) compared the antibacterial effect of GSE with $3 \% \mathrm{NaOCl}$ on E. faecalis [18]. Similarly, Kalluru (2014) demonstrated the effects of several commonly used irrigation solutions on the dentin's microhardness in the root canal [11]. Antibacterial effect and ability to dissolve pulp and necrotic tissue at a concentration of $3 \%$ is superior to those at concentrations of $0.5 \%$ and $1 \%$. Higher concentrations of $\mathrm{NaOCl}$ will exert more toxic effects on the periapical tissue [27].

Until now, there has been no standard regarding the ideal duration of root canal irrigation. Based on an in vitro study by Retamozo et al. (2010), the best effect of irrigation with $5.25 \% \mathrm{NaOCl}$ observed for 40 min. If a lower concentration of $1.3 \%$ or $2.5 \%$ used, the duration 
of $40 \mathrm{~min}$ is not sufficient for removing E. faecalis from the dentinal tubules [28]. In this study, the canal root canal disk was immersed in the test solution for 3 consecutive days, with 30 min of immersion time per day. Based on the clinical simulation of root canal treatment duration, the root canal was exposed to irrigation solutions for 30 min every appointment.

Several studies on the use of GSE as a root canal irrigation solution have employed different application methods. In the study by Cecchin (2015), dentin plates were soaked for $40 \mathrm{~min}$ in the test solution to compare the effect of $2.5 \% \mathrm{NaOCl}$ and $6.5 \%$ GSE on the dentin's flexural strength [6]. Whereas in the study by Manimaran (2011), GSE's effect with $5 \%$ proanthocyanidin on the bonding strength of the sealer to the dentin after root canal irrigation with $5.25 \% \mathrm{NaOCl}$ evaluated; the GSE solution used as a final irrigation solution for $10 \mathrm{~min}$ [5].

Further research evaluating the effects of various durations of application of the solution is warranted. Exposure to the irrigation solution was related to variations in the endodontic treatment time by different clinicians. Thus, by adding the time of application of the test solution as a variable, the most effective duration of GSE solution as irrigation can be discovered.

\section{Microhardness measurement method}

Several methods used to measure microhardness, and the two most common methods are the Vickers and Knoop methods [13]. In this study, the Vickers method used because it can evaluate surface changes in the deeper hard tissues of the teeth, whereas Knoop hardness testing more commonly used for surface dentin (depth, $0.1 \mathrm{~mm}$ ) [13]. The microhardness value obtained on the dentinal root canal plate after being exposed to a load of $500 \mathrm{~g}$ in $15 \mathrm{~s}$ has determined by its indentation point [14].

The dental root canal plate used in this study originated from the apical one-third of the dentin root canal. This section chooses because the density of this area after a root canal filling is one of the determinants of the success of the treatment [29]. Microhardness is one of the factors that influence the level of sealer adhesion obturation in the dentin root canal.

\section{GSE solution effect to dentin's microhardness}

The results of the statistical tests in this study (Table 1) show that there are significant differences $(\mathrm{p}=0.002 ; \mathrm{p}<0.05)$ in the dentinal root canal microhardness values among the GSE (32.21 \pm 15.14 ), $\mathrm{NaOCl}(21.24 \pm 9.23)$, and distilled water $(29.55 \pm 12.63)$ groups. Thus, both GSE with a proanthocyanidin content of $2.9 \%$ and $3 \% \mathrm{NaOCl}$ influenced the dentin root canal microhardness. The microhardness of the GSE group was higher than those of the $\mathrm{NaOCl}$ and distilled water groups. The microhardness value of the GSE group showed higher results compared to the $\mathrm{NaOCl}$ group $(\mathrm{p}=0.002)$. Likewise, the GSE group's microhardness was higher than that of the distilled water group, statistical significance notwithstanding $(p=0.631)$. The $3 \%$ $\mathrm{NaOCl}$ solution can reduce dentin root canal microhardness, while the GSE solution with proanthocyanidin $(2.9 \%)$ is not proven to be able to improve the microhardness. The mean value of dentin root canal microhardness in the GSE group $(32.21 \pm 15.14)$ was higher than that of the distilled water group (29.55 \pm 12.63$)$, although the difference was not statistically significant ( $p>0.05$ ). Thus, it may conclude that GSE can maintain the microhardness of the dentin root canal.

$\mathrm{NaOCl}(3 \%)$ solution has shown to significantly reduce the microhardness of the dentin in the root canal [11]. The microhardness in the $\mathrm{NaOCl}$ group $(21.24 \pm 9.23)$ was lower than those in the distilled water $(29.55 \pm 12.63)$ and $(32.21 \pm 15.14)$ GSE groups. These findings clearly show that $3 \%$ of $\mathrm{NaOCl}$ can reduce dentin's microhardness in the root canal.

\section{The role of proanthocyanidin in GSE}

In this study, the role of proanthocyanidin in GSE as a cross-linking agent of collagen, which can increase dentin microhardness, did not differ significantly compared with distilled water control solution. This condition possibly caused by the content of glycerin in the GSE solution used. Glycerin as a thickener increases the GSE solution's surface tension so that the penetration into the dentinal tubules will be lower. Therefore, the role of proanthocyanidin molecules in GSE solution with glycerin could not be optimum to increase the microhardness of dentin in the root canal. In a previous study by Liu et al. (2015), the small molecular size of proanthocyanidin reported providing the best results in triggering an increase in dentin collagen's mechanical properties [30].

The microhardness evidenced by mineral loss or an increase in the hard tooth tissue and indirectly illustrates the extent of collagen matrix bonding in the dentin. Dentin microhardness is determined by the strength of the collagen matrix bonding to the dentin and the number of calcified matrices per $\mathrm{mm}^{2}$ [19]. The collagen matrix's amount and stability in the dentin root canal will affect the strength of the adhesion of the resin-based sealer to the dentin. Application of GSE with 5\% proanthocyanidin shown to increase the adhesive strength of the resin to a root canal that irrigated with $5.25 \%$ of $\mathrm{NaOCl}$ [5].

Proanthocyanidin molecules consist of free hydroxyl groups that form bridge-type hydrogen bonds with the side chains of hydroxyl, carboxyl, amino groups, and collagen amides. These hydrogen bonds account for the stability of the proanthocyanidin-collagen interactions. Furthermore, due to its position between the collagen molecules, proanthocyanidin can form ionic and covalent bonds with collagen fibrils. The proanthocyanidin molecules replace the water molecules that bind to collagen in the extra fibrils to form these hydrogen bonds.

Proanthocyanidin stabilizes and enhances the cross-linking of type I collagen fibrils by proline hydroxylation, an essential stage of collagen biosynthesis. Thus, the collagen cross-links are more stable in the dentin matrix. Intermolecular cross bonds determine the stability, strength, and viscoelasticity of the collagen fibrils. Collagen fibrils reinforced by cross-linking agents such as proanthocyanidin will have increased mechanical properties and reduced enzymatic degradation, which plays essential roles in material adhesion to the dentin [2].

\section{CONCLUSION}

The findings of this study show that GSE can increase the dentin's microhardness in the root canal. GSE solution can be used as an irrigation material during root canal treatment, and a solution containing $2.9 \%$ of proanthocyanidin can maintain the microhardness of the root canal dentin.

Further research is needed to evaluate the microhardness of the root canal using GSE in conjunction with various irrigation techniques and durations; also, the effect of local GSE from Indonesia containing various concentrations of proanthocyanidin needs evaluation.

\section{FUNDING}

Nil.

\section{AUTHORS' CONTRIBUTIONS}

All the authors have contributed equally.

\section{CONFLICTS OF INTEREST}

Declared none.

\section{REFERENCES}

1. Muliyar S, Shameem KA, Thankachan RP, Francis PG, Jayapalan CS, Hafiz KA. Microleakage in endodontics. J Int Oral Health 2014;6:99-104.

2. Castellan CS, Pereira P, Viana G, Chen SN, Pauli GF, BedranRusso AK. Solubility study of phytochemical cross-linking agents on dental stiffness. J Dent 2010;38:431-6.

3. Vire D. Failure of endodontically treated teeth: Classification and evaluation. J Endod 1991;17:338-42. 
4. Zakarea NA, Mohamad TH, Taqa AA, Chumbley S, Al-Juaid S, Balto $\mathrm{H}$. A newly prepared solution for the removal of the smear layer. Int J Dent Sci Res 2014;2:19-26.

5. Ebenezar AR, Srinivasan N, Manimaran VS, Srinivasulu S, MahalaxmiS. Application of a proanthocyanidin agent to improve the bond strength of root dentin treated with sodium hypochlorite. J Conserv Dent 2011;14:306.

6. Cecchin D, Farina AP, Souza MA, Albarello LL, Schneider AP, Vidal CM, et al. Evaluation of antimicrobial effectiveness and dentine mechanical properties after use of chemical and natural auxiliary irrigants. J Dent 2015;3:3-10

7. Bedran-Russo AK, Karol S, Pashley DH, Viana G. Site specific properties of carious dentin matrices biomodified with collagen crosslinkers. Am J Dent 2013;26:244-8.

8. Tang C, Fang M, Liu R, Dou Q, Chai ZG, Xiao YH, et al. The role of grape seed extract in the remineralization of demineralized dentine: Micromorphological and physical analyses. Arch Oral Biol 2013;58:1769-76.

9. Angellina AV. Potensi Ekstrak Biji Anggur Sebagai Larutan Irigasi Saluran akar Dalam Membersihkan Smear Layer, Tesis. Indonesia: Universitas Indonesia Library; 2013

10. Soetanto S. Kemampuan Antibakteri Larutan Ekstrak Biji Anggur Dengan Kadar Tanin 2, 9\% Terhadap Biofilm. Indonesia: Faecalis Universitas Indonesia Library 2014.

11. Kalluru RS. Comparative evaluation of the Effect of EDTA, EDTAC, $\mathrm{NaOCl}$, and MTAD on microhardness of human dentin an in-vitro study. J Clin Diagn Res 2014;8:39-41.

12. Sultana S, Nikaido T, Tagami J, Matin K. Storage media to preserve dentin and their effects on surface properties. Int China J Dent 2006;6:123-9

13. Kandil HE, Labib AH, Alhadainy $\mathrm{H}$ a. Effect of different irrigant solutions on microhardness and smear layer removal of root canal dentin. Tanta Dent J 2014;11:1-11.

14. Aslantas EE, Buzoglu HD, Altundasar E, Serper A. Effect of EDTA, sodium hypochlorite, and chlorhexidine gluconate with or without surface modifiers on dentin microhardness. J Endod 2014;40:876-9.

15. Ghorbanzadeh S, Loodaricheh SA, Samizade S, Zadsirjan S. Irrigants in endodontic treatment. Int J Contemp Dent Med Rev 2015;11:12.
16. Mathew ST. Risks and management of sodium hypochlorite in endodontics. J Oral Hyg Health 2015;03:1-5

17. Iampaglia SD. Effect of Bioactive Irrigants on Intraradicular Dentin Microstructure during Endodontic Therapy. Chicago: University of Illinois at Chicago: 2012

18. Ghonmode WN, Balsaraf OD, Tambe VH, Saujanya KP, Patil AK, Kakde DD. Comparison of the antibacterial efficiency of neem leaf extracts, grape seed extracts and $3 \%$ sodium hypochlorite against E. faecalis an in vitro study. J Int Oral Heal 2013;5:61.

19. White DJ, Faller RV, Bowman WD. Demineralization and remineralization evaluation techniques--added considerations. J Dent Res 1992;71:929-33.

20. Bahrami P. Effects of $10 \%$ carbamide peroxide on fracture toughness and microhardness of human dentin in situ. Oper Dent 2012;38:142-50.

21. Epasinghe DJ. Applications of Proanthocyanidin in Dentistry. Pokfulam, Hong Kong: The University of Hong Kong; 2014.

22. Budiyati E. Prospek Pengembangan Varietas-varietas Unggul Anggur di Daerah Sentra Produksi. Indonesia: Balitjestro; 2012.

23. Prihatman K. Budidaya Pertanian: Anggur. Jakarta, Indonesia: BAPPENAS; 2000.

24. Widyastuti Y, Paimin F. Mengenal Buah Unggul Indonesia. Jakarta: Swadaya; 1993.

25. Liu Y, Dusevich V, Wang Y. Proanthocyanidins rapidly stabilize the demineralized dentin layer. J Dent Res 2013;92:746-52.

26. Srinivasulu S, Vidhya S, Sujatha M, Mahalaxmi S. Effect of collagen cross-linkers on the shear bond strength of a self-etch adhesive system to deep dentin. J Conserv Dent 2013;16:135-8.

27. Marion JJ, Manhães FC. Efficiency of different concentrations of sodium hypochlorite during endodontic treatment. Literature review. Dent Press Endod 2012;2:3-8.

28. Retamozo B, Shabahang S, Johnson N, Aprecio RM, Torabinejad M. Minimum contact time and concentration of sodium hypochlorite required to eliminate Enterococcus faecalis. J Endod 2010;36:520-3.

29. Chaudhari A, Asthana G, Parmar G, Vadher R, Kaur M. Significant of apical third: A review. Sch J Appl Med Sci 2014;2:1613-7.

30. Liu Y, Bai X, Li S, Liu Y, Keightley A, Wang Y. Molecular weight and galloylation affect grape seed extract constituents ability to cross-link dentin collagen in clinically relevant time. Dent Mater 2015;31:814-21. 